\title{
ANTONIO CANDIDO: \\ LEITOR DE MACHADO DE ASSIS - NACIONALISMOS E ROMANTISMOS
}

\section{GUILHERME RODRIGUES}

Universidade Estadual de Campinas, Campinas, São Paulo, Brasil

Resumo: Este artigo propõe a análise da leitura da obra machadiana por Antonio Candido, recorrendo principalmente a dois textos do crítico: "Música e música" e "Esquema de Machado de Assis".

Palavras-chave: Antonio Candido; Machado de Assis; Nacionalismo; Romantismo; Literatura brasileira.

\section{ANTONIO CANDIDO: READER OF MACHADO DE ASSIS - NATIONALISM AND ROMANTICISM}

Abstract: This article proposes the analysis of Antonio Candido's reading of Machado de Assis's work by referencing two of Candido's texts: "Music and Music" and "An Outline of Machado de Assis".

Keywords: Antonio Candido; Machado de Assis; Nationalism; Romanticism; Brazilian Literature.

é proposto no segundo prefácio da Formação da literatura brasileira, a literatura brasileira entendida plenamente como sistema que depende do eixo autor-obra-público "se configura no decorrer do século XVIII, encorpando o processo formativo, que vinha de antes e continuou depois" (CANDIDO, 1975, v. 1, p. 16). Entre os fenômenos de consolidação desse sistema literário, a criação de um cânon foi mister, o que, pela natureza tributária da literatura brasileira à portuguesa, criou uma dependência das experiências europeias desta arte (CANDIDO, 1975, v. 1, p. 10). Assim, durante o século XIX se desenvolveu o que se pode chamar de 
princípios de uma crítica literária, que, caracteristicamente romântica, se associaria a um espírito relativista, individualista e histórico, buscando de modo central a consciência nacional de literatura. Dessa maneira, este movimento se esforçou por criar uma história literária própria, contra uma suposta imposição cultural externa.

Durante o último movimento de sua obra, Antonio Candido desenvolveria como a formação da consciência da literatura brasileira se deu no mesmo processo que acompanhou a construção da crítica oitocentista, descendendo da teoria romântica franco-germânica (CANDIDO, 1975, v. 2, p. 319). Assim, o Romantismo brasileiro tentou se fundamentar na construção de um imaginário local nacionalista que afirmasse a cor local, ainda que a forma fosse tributária daquelas europeias, o que levou à constituição de subjetividades clivadas, em que se notaria uma visão de Brasil a partir dos olhares dos europeus, "propiciando, nas letras, a exploração do pitoresco no sentido europeu, como se estivéssemos condenados a exportar produtos tropicais também no terreno da cultura espiritual” (CANDIDO, 1975, v. 2, p. $324)$.

A percepção de Candido a respeito da consolidação de uma consciência literária brasileira nos Oitocentos demonstra, então, a centralidade de dois conceitos, um intrinsecamente ligado ao outro: i. universalismo; ii. localismo. Especialmente no que tange a obra de Machado de Assis, esses dois conceitos foram utilizados em demasia de maneira oposta, tentando sobretudo encaixar a obra do escritor em contraposição a seus contemporâneos, ora considerando-o como um vanguardista, ora como tributário de uma tradição passada e fora de seu lugar no eixo da construção da nacionalidade de espírito romântico; ora profundamente brasileiro, ora estrangeiro demais.

Assim, este artigo propõe observar a percepção de Antonio Candido a respeito da obra de Machado de Assis, passando especialmente por dois de seus textos críticos mais famosos sobre o escritor: "Música e música", publicado originalmente no suplemento literário do jornal O Estado de S.Paulo em 1958; e "Esquema de Machado de Assis", produzido para ser lido nos Estados Unidos, durante o primeiro semestre de 1968. Ademais, procura-se desenvolver como a análise de Candido da obra machadiana dialoga com as linhas principais de sua crítica literária, a saber, a percepção da individualidade de cada obra, levando-o a pensar cada uma partindo dela mesma no seu método sem método, sob o interesse de saber como o externo se transforma em interno e assim explicar o que ele mesmo chamaria de busca do aparente pelo oculto. 
Em entrevista publicada em 1979, Candido menciona que seu ato crítico se dividira até então em três momentos: i. nos anos 1940, haveria uma preocupação a respeito dos condicionamentos da obra literária, seguindo o que o crítico chama de uma veia marxista-positivista; ii. chamado de antitético por ele mesmo, influenciado pela antropologia social inglesa e pelo New Criticism, Candido se debruçou no que nomeia como funcionalidade, conceito que ele vê bem acabado em seus escritos da década de 1950, entre eles a Formação; e iii. na década de 1960, sua preocupação de caráter funcional seria absorvida pela estrutura, fazendo diferente dos estruturalistas por se indagar "como a estrutura se estrutura", ou seja, em que medida o externo se torna interno (CANDIDO, 1992, p. 232-233).

Como observou Schwarz, a análise estética de Candido traria uma inspiração da antropologia e da sociologia, ainda que a seu modo, ao focar nos processos de estruturação das obras literárias sem perder de vista seus aspectos sociais (SCHWARZ, 1999, p. 12-13).

Observe-se como isso está colocado no prefácio à terceira edição de 1972 de seu livro Literatura e sociedade, em que o crítico aponta que "a estrutura constitui aspecto privilegiado e ponto de referência para o trabalho analítico" e destaca ainda que o uso de um conceito de estruturalismo não seria aquele frequentemente empregado a partir dos anos 1970, tentando articular a estrutura de modo central à circunstância onde mergulha a obra e sua função (CANDIDO, 2019, p. 9-10) - o que poderia ser visto no sintagma autor-obrapúblico, que põe a obra no centro do autor e público.

O que se coloca como ponto de partida e chegada na leitura crítica de Candido é a obra, fazendo das variações externas fenômenos reduzidos na estrutura da mesma, o que faz com que ele identifique na própria obra componentes profundos mesmo quando seu olhar parece se afastar dela. ${ }^{1}$ Assim, Arantes também notaria que o crítico, ao articular "um campo histórico de influências artísticas cruzadas", dava com o problema geral da formação no Brasil e respondia com esse movimento de profundidade dialética (ARANTES, 1997, p. 19-22). Haveria nisso, portanto, uma consciência de uma autonomia da obra frente ao que se pode chamar de história da literatura, questão vista também por Benjamin - o que torna talvez possível uma ligação da crítica de Candido à do alemão, já que nela "não se trata, realmente, de apresentar as obras literárias no contexto geral de seu tempo, mas sim de levar

\footnotetext{
${ }^{1}$ Note, por exemplo, como Schwarz observará esse movimento na análise feita do romance $O$ cortiço (SCHWARZ, 1999, p. 26-28).
} 
à representação, no tempo em que surgiram, do tempo que as reconhece - e que é o nosso" (BENJAMIN, 2018, p. 138).

É dessa maneira que o conceito de Candido chamado redução estrutural se vê bem desenvolvido em seu ensaio sobre as Memórias de um sargento de milícias. Ali ficará explícito como se entende que "o que interessa para a análise literária é saber, nesse caso, qual a função exercida pela realidade social historicamente localizada para constituir a estrutura da obra" (CANDIDO, 2010, p. 28).

Entendido de maneira dialeticamente íntegra, busca-se compreender como a totalidade da obra compõe o fator externo "não como causa, nem como significado, mas como elemento que desempenha um certo papel na constituição da estrutura, tornando-se, portanto, interno", como se o detalhe e as partes pudessem ser percebidos em relação à formação do todo, desse modo não somente a pergunta se voltaria para a influência do meio sobre a obra, mas também o contrário (CANDIDO, 2019, p. 14, 18, 28).

$\mathrm{Na}$ formação de sua crítica, no sentido de seu desenvolvimento, como Antonio Candido expõe, os dois escritos sobre Machado de Assis se encaixariam nos dois momentos derradeiros descritos na entrevista, de modo que a consciência do movimento dialético formado a partir da análise de Machado de Assis apontará para um escritor que não somente reduziu estruturalmente os fenômenos de seu tempo como o fez de modo exclusivo a se tornar um autor de maior qualidade entre seus pares. ${ }^{2}$ Assim, haveria nos estudos de Candido, em primeiro lugar, uma preocupação com a função da musicalidade na obra machadiana, sobretudo no romance Memorial de Aires, e seguidamente uma leitura do autor na história da crítica levando em consideração a estrutura e o modo de estruturação da obra do escritor.

Em ambos os casos, Candido analisa seu objeto abrindo o leque da literatura brasileira, contemporânea ao escritor e posterior a ele, ou seja, pensando na estrutura literária e na função histórica do texto machadiano em relação a seu desenvolvimento no tempo e no espaço nacionais, evocando o espírito do Romantismo e do Modernismo como comparações. Assim, podese dizer que "não será demais afirmar que a meditação sobre a carreira exemplar de Machado de Assis terá sido decisiva" para a constituição da crítica do autor, na medida em que se veria nele - "esse mestre admirável" -, em comparação a seus contemporâneos, uma síntese bem articulada da

\footnotetext{
${ }^{2}$ Note-se como Schwarz analisará num capítulo de seu livro as Memórias póstumas de Brás Cubas para argumentar sobre esse processo, se utilizando do conceito de Candido (SCHWARZ, 2012, p. 35).
} 
dialética universal x local, ${ }^{3}$ diagnóstico notado sobretudo no romance, gênero em que conseguiu ao mesmo tempo reconhecer seus predecessores e superálos, e por isso "é o escritor mais brasileiro que jamais houve, e certamente o maior" (CANDIDO, 1975, v. 2, p. 115-118). Com este grande escritor, portanto, o que seria demonstrada como a formação da literatura brasileira se dava, porque a obra dele poderia se explicar pela integração de um sistema literário nacional maduro (SCHWARZ, 1999, p. 18).

Em relação aos contemporâneos de Machado de Assis, Candido desenvolve seu argumento na Formação aludindo a uma consciência dilacerada entre a formação dos românticos e naturalistas no Brasil, um misto de imaginação livre e forma escrava da literatura nacional (CANDIDO, 1975, v. 2, p. 346): sua consciência da literatura se daria num embate entre o que é local e o que é universal, sendo aquele os temas intimamente ligados ao que se entende pela nação nascente e este àquilo que advém da cultura europeia e, portanto, a literatura clássica estaria ligada aos tempos de colônia que deveriam ser repudiados em favor de uma inspiração dada pela cor local (CANDIDO, 1975, v. 2, p. 328-329). Há na obra de Candido um argumento de que essa afirmação se daria mais como um ato consciente de vontade do que como uma visão objetiva do estado das letras brasileiras, à medida que uma série de dificuldades (materiais e estéticas) tornavam o estabelecimento de uma literatura tipicamente nacional um exercício claudicante. ${ }^{4}$ De certa maneira, o crítico examina a formação da literatura nacional no caminho de uma autonomia estética em relação aos europeus, especialmente os portugueses, porém essa tensão, que é apontada por Antonio Arnoni Prado, funcionaria ao contrário do que se poderia entender como uma consciência autônoma.

Neste sentido, Candido sugere na Formação que há um estímulo das narrativas europeias de viagem sobre o Brasil antes de 1822, na constituição desse pensamento romântico, já que essas histórias demonstravam uma exaltação da beleza natural do país (CANDIDO, 1975, v. 1, p. 280-281) - o que viria a ser um dos temas mais caros aos brasileiros de então. Contudo, os mais influentes nesses primeiros "respiros" de Romantismo no Brasil seriam os franceses, ou franco-brasileiros, instalados na colônia da Tijuca.

Seguindo esse modelo, a literatura nacional se inspiraria na beleza da paisagem, além de se conduzir subjetivamente por poemas que tematizassem

\footnotetext{
${ }^{3}$ Argumento este que se sustenta também na menção, ainda que breve, de um equilíbrio dessa dialética encontrada na obra de Machado de Assis (CANDIDO, 2019, p. 117).

${ }^{4}$ Há uma série de momentos em que se verifica isso na obra de Antonio Candido, note-se apenas um exemplo em Literatura e sociedade, 2019, p. 177-178.
} 
o índio como um povo mítico e até mesmo iniciador da poesia local, entendendo-a como cultura extinta de um passado longínquo. Essa temática se desenvolveu em narrativas como as Cenas da natureza sob os trópicos de Denis, na qual se sistematizam notoriamente as impressões causadas pela natureza brasileira; nas palavras de Candido: um "naturismo extático" advindo de Chateaubriand e Madame de Staël (CANDIDO, 1975, v. 1, p. 283; v. 2, p. 321-325). Sua fórmula e sugestão de tomar os quadros brasileiros de empréstimo para a literatura segue linhas liberais famosas na Europa de então, especialmente advindas de um nacionalismo revolucionário pós-Revolução Francesa, e aponta para uma tentativa de resgate de um passado distante, para, a partir daí, destacar os gênios da tradição literária.

Deste modo, Candido argumenta que "o Romantismo brasileiro foi tributário do nacionalismo", ainda que nem todas as suas manifestações se enquadrassem estritamente nele; mas haveria sobretudo uma busca por autonomia, entendida assim como uma independência temática, dada pela soberania do tema local (CANDIDO, 1975, v. 1, p. 15).

Ainda se aponta como essa tensão haveria de ser superada com Sílvio Romero e sua vertente naturalista, indicando como um de seus traços fundamentais o reconhecimento de uma literatura do passado que anunciara aquelas correntes românticas então presentes (CANDIDO, 1975, v. 2, p. 329330). Assim, está desenvolvido o ensaio "Estrutura literária e função histórica", de 1961, que argumenta como o espírito da época de então preconizava o pensamento de que "ser bom, literariamente, significava ser brasileiro; ser brasileiro significava incluir nas obras o que havia de específico do país, notadamente a paisagem e o aborígene" (CANDIDO, 2019, p. 178).

Essa tendência seria seguida por outra: uma busca genealógica da literatura; mas ela enfrentaria a dificuldade de esbarrar no que o crítico chama de um país sem tradições, acarretando numa mescla de história e nobiliarquia, e num mito de uma nobreza indígena redentora da mestiçagem - fenômeno que talvez possa ser vislumbrado com toda a força em Ubirajara e Iracema de José de Alencar. É dessa maneira, portanto, que se estruturaria de forma ambígua o poema de Santa Rita Durão, Caramuru, já que seu princípio organizador norteado pela ideologia da catequese conecta a representação local da colonização e a universal do catolicismo: assim demonstra-se o que seriam os princípios românticos da imaginação livre numa forma escrava. Argumenta-se que o nacionalismo do qual é tributário o pensamento romântico no Brasil do século XIX foi inventado sob princípios literários ambíguos que mesclariam um localismo e um universalismo, pautados sob 
uma estrutura que organiza arbitrariamente suas variáveis dentro das obras, isto é, se coloca em questão o conceito mesmo de nacionalismo.

Em estudo de 1984, o crítico percorre os significados do nacionalismo no século XX, evocando diversas vezes o que se chama de nacionalismo ornamental ou compensatório. Este seria uma forma de esconder ou relevar as mazelas que assolam um país cuja consciência de subdesenvolvimento é nascente na primeira metade do século XX. Haveria nessa ideia uma tentativa de particularismo e diferenciação do europeu, num fluxo de independência intelectual. Assim, a figura de Olavo Bilac e sua visão patriótica marcaria esse nacionalismo ornamental e ufanista, cujo ponto de vista ideológico exprime a imagem do Brasil que excluiria as classes desfavorecidas do país (CANDIDO, 2011, p. 218-219). Essa perspectiva seria contraposta àquela presente na obra de Euclides da Cunha, bem como na representação das Memórias sentimentais de João Miramar e Macunaíma: três representações de um Brasil bastante diverso do tom patriótico ufanista da poesia de Bilac ou do afã fascista dos verde-amarelos.

A tentativa de estabelecimento de um certo sentimento nacional no século XIX, principalmente durante o Segundo Império, não seria algo muito distinto do embate que a seguiria. Isso se daria em primeiro lugar pela posição da doutrina romântica supramencionada, que seria seguida pela perspectiva naturalista de Sílvio Romero, ainda muito similar ao Romantismo, mas com o vetor inverso: objetiva-se evidenciar as mazelas nacionais originárias do meio físico, e não louvá-las, fator evidente em uma obra como $O$ cortiço.

É notável como a descrição de Iracema no capítulo dois do romance de Alencar (2012, p. 99) é similar à de Rita Baiana no capítulo sete de Azevedo (2012, p. 152), já que em ambos a comparação se dá com o meio físico e com a fauna -, sendo que se diferencia em Iracema pela corrida da ema (palavra que ecoa poeticamente no próprio nome da personagem) e em Rita pela peçonha da lagarta, da cobra e da muriçoca; ademais, em ambas a equiparação paisagística aproxima a palmeira e a baunilha das personagens, além da sensação de dulçor evocada juntamente com a sensação odorífera. Essa aproximação não fugiu ao entendimento de Candido, que afirma que "Iracema e Rita são igualmente o meio" (CANDIDO, 2010, p. 123), além de desenvolver na Formação a ideia de que o romance naturalista pouco avançou quanto ao dilaceramento da subjetividade e da estética românticas (CANDIDO, 1975, v. 2, p. 117).

A redução estrutural de elementos similares em dois textos que apresentam perspectivas tão diversas pode apontar para uma consciência 
nacional de mesma origem, ou no mínimo para um reconhecimento dos mesmos objetos, já que, entendida pelo crítico enquanto construção de objetos autônomos com estrutura e significado e uma forma de expressão que manifesta visões de mundo, a literatura seria uma forma de conhecimento que pode incorporar fenômenos inconscientes de indivíduos e grupos (CANDIDO, 2011, p. 178-179). Talvez seja por esse motivo que Machado de Assis por muito tempo foi tomado como pouco brasileiro, ou ainda, avesso a um sentimento nacional e, no limite, alienado das coisas locais.

Contudo, Antonio Candido analisa o escritor de forma diferente - para o crítico, Machado seria o mais maduro dos escritores brasileiros, o que foi capaz de articular melhor que seus pares a dialética que envolve a formação da literatura nacional. ${ }^{5}$ É notável, porém, que o crítico aponte como uma falha no estudo de Machado a exclusão da obra dita romântica do escritor, Candido discorda que a obra suscite uma espécie de seção, pois ela é "uma obra cuja unidade é cada vez mais patente aos estudiosos” (CANDIDO, 1975, v. 1, p. 12). Alguns anos depois, Candido reforçaria, em O Romantismo no Brasil, a observação anterior; que nos anos 1870 no Brasil, a atividade literária do escritor foi marcante, ainda que não se pudesse prever que Machado suplantasse aquele nível após 1880, quando se verifica a maior originalidade e força de seu estilo (CANDIDO, 2004b, p. 71).

As observações fortalecem um fator que parece essencial tanto na obra machadiana quanto em sua recepção: a ausência desse sentimento nacional paisagístico ou indianista, como discutido anteriormente, fator este presente desde suas primeiras poesias, romances e contos. Sendo assim, parece plausível que a análise da obra machadiana proposta por Candido chame a atenção para essa aversão e, em certo sentido, dê uma unidade para a obra e não uma cisão brutal em dois momentos, como é proposto por Schwarz, após a publicação das Memórias póstumas de Brás Cubas. ${ }^{6}$

Assim, Candido publica no suplemento literário d'O Estado de S. Paulo em 1958 o artigo "Música e música” em que se debruça sobre Memorial de Aires, derradeiro romance de Machado. Inicia-se o artigo com uma conjectura para se desenvolver o problema: "Machado de Assis foi bastante musical."

\footnotetext{
${ }^{5}$ Tome-se a maneira como é finalizado o último capítulo da Formação, o processo acabaria com o ponto de realização da maturidade da literatura brasileira, verificada em "Instinto de nacionalidade" de Machado.

${ }^{6}$ Ressalte-se, porém, que Candido chega a mencionar a divisão da obra de Machado especialmente com relação à forma e ao tamanho dos capítulos dos romances de 1870 e aqueles posteriores às Memórias, além da presença patente de uma interconexão difusa entre eles, o que demonstraria a envergadura do escritor ao reduzir estruturalmente a clivagem subjetiva que se verifica nos romances do século XVIII (CANDIDO, 2004a, p. 125-129).
} 
Interessantemente, aquilo para que o crítico chama a atenção é que a presença da música na obra é "leve, parecendo mais recurso de composição e análise do que propriamente emoção profunda.” (CANDIDO, 2008, p. 27) Ou seja, notase que há um fenômeno de incorporação de um elemento externo - a música - à internalidade da obra de modo estruturante, isto é, o fenômeno do mundo é reduzido e organizado como marca da forma literária, o que adquiriria uma função nesse processo de estruturação.

A análise do referido romance machadiano parte de um episódio em que o casal Fidélia e Tristão (nomes oriundos de óperas de Beethoven e Wagner, como relembra o artigo) tocam piano para o deleite dos Aguiar e do conselheiro Aires. O texto desvela como a função da música no episódio de 31 de agosto do romance-diário vai "alinhavar as partes de uma cena mundana" (CANDIDO, 2008, p. 28) a um "elemento central de composição, estruturando o texto e constituindo o seu movimento psicológico profundo" (CANDIDO, 2008, p. 30). A cena aparece inicialmente como uma atividade de fim de tarde da elite brasileira frequentadora dos teatros fluminenses no fim do Império e, conforme as observações do narrador, ela se encaminha para um modo de pensar a paixão vindoura (ainda desconhecida pelo redator do diário, pois ela acontecerá somente no ano seguinte) e também meditar sobre os Eus frustrados: a música foi uma das inclinações e hoje é uma das saudades do conselheiro (ASSIS, 2008, p. 90-91). Candido finaliza seu ensaio comparando a meditação musical do conselheiro Aires à do protagonista d'O Ateneu de Raul Pompeia, mencionando como em $O$ Ateneu os sons são descritos com densidade sensorial ao gosto naturalista, o que faria o corpo todo de Sérgio reagir ao seu influxo, "traduzindo a emoção em palpitação cardíaca" (CANDIDO, 2008, p. 32).

Nesse breve artigo de Candido percebe-se como Machado de Assis se diferencia de um de seus contemporâneos, cujo romance está no cânone brasileiro: um possuiria a verve naturalista, cujos princípios estruturantes adviriam da consciência localista; o outro proporia uma redução desse elemento a um princípio de estrutura de meditação existencial, cuja linha segue a reflexão das frustrações e do envelhecimento, como é sugerido ao fim do artigo. Ora, o que se propõe, então, é perceber como de fato a obra de Machado de Assis não se encaixaria sob um princípio da evidência localista pelas linhas naturalistas, mas incorporaria a prática cultural da elite imperial sob uma ótica mais universal. Do mesmo modo que Candido notará que Bastide aponta a redução da paisagem na composição das personagens de Dom Casmurro (CANDIDO, 2004a, p. 115-121) e que a incorporação da música se 
apresenta no Memorial como uma sonata que só mesmo chamando de demoníaca, como afirma o crítico (CANDIDO, 2017, p. 8).

Haveria uma face mortificadora na negação de tudo e no alheamento do conselheiro ao redigir seu diário, enquanto vê o enlace dos jovens da elite brasileira seguindo os mesmos passos da velha elite, da qual o narrador faz parte. Há a apresentação de um problema insolúvel quanto à tentativa de resolução desses temas que se desenvolvem no Memorial à maneira de uma sonata amputada de sua coda. Poderíamos ainda afirmar como essa redução se faz ver na negação dos problemas ali colocados, que em si falha e se fratura, formando a verdadeira obra de arte que é o romance machadiano.

Como argumenta Vladimir Safatle sobre a música de Schoenberg e Berg, a música toma "o estado arruinado da linguagem própria a uma sociedade que toda obra de arte verdadeira combate" e ela "saberá fazer das determinações significativas da linguagem anterior fraturas, fragmentos” (SAFATLE, 2019, p. 71). Essa estruturação tipicamente musical que se vê no romance de Machado de Assis foi descrita por Candido pelos moldes da redução estrutural, que busca notar também o potencial transformador de uma dialética negativa de um dos "negadores mais completos que se conhece" (CANDIDO, 2017, p. 9).

Dez anos depois, num texto preparado para apresentar o escritor fluminense em duas universidades nos Estados Unidos, Candido propõe um panorama da obra de Machado de Assis em "Esquema de Machado de Assis". O ensaio sugere no início um certo patetismo romântico nas biografias do escritor - ressalvando a de Jean-Michel Massa - por conta da apresentação de um homem muito bem-sucedido na sua vida pública, um escritor reconhecido e o primeiro presidente da Academia Brasileira de Letras "no bom e no mau sentido" (CANDIDO, 2011, p. 16).

Ao analisar a obra, o ensaio sugere que o desconhecimento a respeito de Machado e de suas notáveis qualidades e de seu caráter vanguardista, que anteciparia a ficção do século XX, se deveria à língua portuguesa e à sua característica marginal, que colocaram na obscuridade uma série de escritores, entre eles Eça de Queirós. A primeira parte do ensaio termina destacando a atualidade intemporal do estilo machadiano e de seu universo oculto "que sugere os abismos prezados pela literatura do século XX" (CANDIDO, 2011, p.18). Note-se aqui como se dá corpo ao que foi dito na Formação a respeito do escritor, enquanto ponto de chegada da maturidade das letras nacionais, tendo Machado de Assis conseguido se tornar um verdadeiro autor universal, ainda que local. 
A segunda parte do ensaio cuida de revisar a fortuna crítica machadiana de modo panorâmico até então. Argumenta-se que a sua boa linguagem sempre foi associada à ironia, incorrendo em subentendidos e ambiguidades diversas "num momento em que os naturalistas atiravam ao público assustado a descrição minuciosa da vida fisiológica” (CANDIDO, 2011, p. 19). Neste primeiro Machado encontraria-se um tom filosofante, pessimista, com gosto pelos clássicos franceses e ingleses do século anterior. Seguidamente, o texto observa que, a partir da década de 1930, a obra de Machado de Assis começou a ser lida de maneira propriamente psicológica, "de acordo com as disciplinas em moda" (CANDIDO, 2011, p. 20). No decênio seguinte, então, o escritor seria lido pelo viés da sociologia e da filosofia, o que levou a algumas interpretações de cunho biografista, ainda que, aos poucos, se notasse um enfoque na obra e não no homem. Começa aqui a percepção de que a obra de Machado de Assis seria profundamente brasileira, a despeito de afirmativas anteriores contrárias. Ainda assim, Candido chegaria a argumentar nos anos 1990 que Bastide, já nos anos 1940, teria sido um precursor do que ele mesmo tentou fazer com a obra do escritor: a redução estruturante (CANDIDO, 2004a, p. 115).

$\mathrm{Na}$ terceira e maior parte do ensaio, Candido discorre sobre o estilo e as características marcantes da obra do escritor fluminense num panorama amplo, apontando para uma "despreocupação com as modas dominantes e o aparente arcaísmo na técnica” (CANDIDO, 2011, p. 22), o que contrastaria com as "modas" literárias realista e naturalista francesas de então. Este tom machadiano, como será chamado, pareceria bruscamente moderno, estilo que anteciparia Kafka - assim resume o crítico:

A sua técnica consiste essencialmente em sugerir as coisas mais tremendas da maneira mais cândida (como os ironistas do século XVIII); ou em estabelecer um contraste entre a normalidade social dos fatos e sua anormalidade essencial; ou em sugerir, sob aparências do contrário, que o ato excepcional é normal, e anormal seria o ato corriqueiro. Aí está o motivo da sua modernidade, apesar do seu arcaísmo de superfície. (CANDIDO, 2011, p. 23)

Essa modernidade que se vê destacada pelo crítico literário ressalta, novamente, um modo particular de Machado reduzir discursos e modos de falar, agir e pensar das elites brasileiras, quando comparado com seus contemporâneos românticos. Percebe-se que Machado não daria espaço em sua obra a um louvor da terra, nem a um pessimismo "ante a desarmonia do 
mundo" (CANDIDO, 2017, p. 9), mas daria espaço a um decoro que se materializa em "força, drama, ironia, dilaceramento do ser e catástrofe do mundo", enquanto contidos em palavras e gramática equilibradas (CANDIDO, 2017, p. 15).

Desse modo, mencionando a profunda complexidade e diversidade da obra machadiana, o ensaio se propõe a identificar as suas questões mais características: 1 . o problema da identidade; 2 . a relação entre o fato real e o imaginado; 3. o sentido do ato e a sua validade; 4. a aspiração à perfeição; 5. a relatividade dos valores e dos atos; e 6. a transformação do homem em objeto do homem. Nessa direção, poderíamos perceber como haveria nesse diagnóstico algo que Adorno também nota em Paul Valéry: uma grande obra de arte que é desenvolvida por alguém que conhece seu métier e assim se desenrola "naquela boa universalidade que não abandona o particular, mas sim o preserva, levando-o a adquirir certo caráter obrigatório, por força de sua própria dinâmica” (ADORNO, 2012, p. 154-155).

Candido finaliza seu panorama crítico argumentando que "os mais desagradáveis, os mais terríveis dos seus personagens, são homens de corte burguês impecável, perfeitamente entrosados nos mores da sua classe" (CANDIDO, 2011, p. 31). Sua percepção é de como os sigilos da alma humana estão profundamente articulados com uma compreensão das estruturas sociais; contudo, o conselho final do crítico é dos mais provocantes: "não procuremos na sua obra uma coleção de apólogos nem uma galeria de tipos singulares. Procuremos sobretudo as situações ficcionais que ele inventou" (CANDIDO, 2011, p. 32).

Notemos que a leitura feita por Candido da obra de Machado de Assis neste ensaio está pautada pela organização de um universo que interioriza elementos fundamentais da experiência humana, num processo que abre a obra para uma ambiguidade profunda, no sentido que será evocado em "O direito à literatura", já que ela poderia ao mesmo tempo ser um instrumento poderoso de educação e instrução, enquanto também poderia atuar contraditoriamente transcendendo as normas estabelecidas - justamente pelo fato de Machado não ser afeito às modas da época e ter evidenciado fatores que a sociedade gostaria de prescrever, como o clientelismo, a violência, a brutalidade das elites e, acima de tudo, o casuísmo da própria norma.

Novamente, aproximando-se da leitura de Adorno, haveria algo de libertador nesse processo da obra de Machado de Assis. Ao buscar a essência burguesa reduzida estruturalmente e as situações ficcionais inventadas, ao nos deparar com uma realidade que não existe e encarnar a pressão indizível 
exercida sobre o que é humano pelo que meramente existe, ao tentar uma conciliação consigo mesma e se recusar a resolver os problemas ali colocados, a obra se fecha para poder se curar da contingência que a rebaixa diante da força e do peso do real (ADORNO, 2012, p. 161, 163). No sentido forte do termo, a obra de Machado de Assis seria dialética e ambígua, e, assim, estaria imbuída da essência do que seria a literatura: uma experiência humanizadora, porque é contraditória.

Como se buscou discutir, Candido aplica seu método sem método na abordagem da obra de Machado de Assis tanto no espectro específico de um pequeno episódio do Memorial de Aires quanto de modo panorâmico. No primeiro caso, o crítico usa de um lirismo e de um tom filosofante para observar como a pequena entrada do último romance de Machado de Assis estaria propondo um outro tipo de redução de um elemento da vida urbana das elites brasileiras em relação à narrativa naturalista, interiorizando não somente o aspecto, mas o tornando parte da estrutura que monta o texto. Anos depois, em seu panorama, evidencia-se a diversidade da obra machadiana por algumas características que ele julga mais fundamentais e que lhe chamam mais a atenção, trazendo à luz uma leitura específica de um aspecto universal da literatura de Machado de Assis: sua capacidade humanizadora. Em sentido amplo, sugerimos que o próprio ato crítico de Antonio Candido traria esse aspecto humanizador, a partir do que ele mesmo menciona no prefácio da Formação: promover a humanização advinda da literatura por "despertar leitores para o texto analisado" (CANDIDO, 1975, v. 1, p. 9).

\section{Referências}

ADORNO, Theodor W. O artista como representante. In: Notas de literatura

I. 2. ed. Trad. Jorge de Almeida. São Paulo: Duas Cidades; Editora 34, 2012. p. 151-164.

ALENCAR, José de. Iracema. 2. ed. Cotia: Ateliê Editorial, 2012.

ARANTES, Paulo. Providências de um crítico literário na periferia do capitalismo. In: .; ARANTES, Otília Beatriz Fiori. Sentido da formação: três estudos sobre Antonio Candido, Gilda de Mello e Souza e Lúcio Costa. 1. ed. Rio de Janeiro: Paz e Terra, 1997. p. 11-66.

ASSIS, Machado de. Memorial de Aires. 1. ed. Belo Horizonte: Livraria Garnier, 2008. AZEVEDO, Aluísio. O cortiço. 2. ed. Cotia: Ateliê Editorial, 2012.

BENJAMIN, Walter. História literária e ciência da literatura. In: Linguagem, tradução, literatura (Filosofia, teoria e crítica). 1. ed. Trad. João Barrento. Belo Horizonte: Autêntica, 2018. p. 131-138. 
CANDIDO, Antonio. Formação da literatura brasileira. 2 v. 2. ed. Belo Horizonte: Editora Itatiaia; São Paulo: Editora da Universidade de São Paulo, 1975.

. Entrevista. In: . Brigada ligeira e outros escritos. 2. ed. São Paulo: Editora da Universidade Estadual Paulista, 1992. p. 231-46.

. Recortes. 3. ed. Rio de Janeiro: Ouro sobre Azul, 2004a. . O Romantismo no Brasil. 2. ed. São Paulo: Humanitas, 2004b.

Música e música. In: O observador literário. 4. ed. Rio de Janeiro: Ouro sobre Azul, 2008. p. 27-32.

. O discurso e a cidade. 4. ed. Rio de Janeiro: Ouro sobre Azul, 2010.

. Vários escritos. 5. ed. Rio de Janeiro: Ouro sobre Azul, 2011.

"Duas notas" e "Prefácio de um livro". Apresentação Ieda Lebensztayn. Machado de Assis em Linha, São Paulo, v. 10, n. 21, p. 3-15, 2017. Disponível em: <https://www.scielo.br/scielo.php?script=sci_arttext\&pid=S1983-

68212017000200003>. Acesso em: 8 fev. 2021. doi:10.1590/19836821201710211.

. Literatura e sociedade. 13. ed. Rio de Janeiro: Ouro sobre Azul, 2019.

PRADO, Antonio Arnoni. Imaginação e consciência localista. In: FONSECA, Maria Augusta; SCHWARZ, Roberto (Org.). Antonio Candido 100 anos. 1. ed. São Paulo: Editora 34, 2018. p. 317-321.

SAFATLE, Vladimir. Dar corpo ao impossível: o sentido da dialética a partir de Theodor Adorno. Belo Horizonte: Autêntica, 2019.

SCHWARZ, Roberto. Sequências brasileiras. São Paulo: Companhia das Letras, 1999. Um mestre na periferia do capitalismo: Machado de Assis. 5. ed. São Paulo: Duas Cidades; Editora 34, 2012.

GUILHERME RODRIGUES é doutorando em teoria e história literária pela Unicamp e professor de ensino básico. (1D https://orcid.org/0000-0002-5824-2104

E-mail: guilhermefr.iel@gmail.com

Recebido: 17.05 .2020

Aprovado: 19.02.2021

Machado de Assis em Linha, São Paulo, v. 14, p. 1-14, e238184, 2021

Este texto está licenciado sob uma Licença Creative Commons do tipo atribuição BY. 